Office of Naval Research

Department of the Navy

Contract Nonr-220(28)

\title{
STABILITY OF A CONDUCTING FLUID FLOWING DOWN AN INCLINED PLANE IN A MAGNETIC FIELD
}

by

Din-Yu Hsieh

\begin{abstract}
Division of Engineering and Applied Science CALIFORNIA INSTITUTE OF TECHNOLOGY

Pasadena, California
\end{abstract}

Report No. 85-29

Approved by:

December 1964 M. S. Plesset 
Office of Naval Research

Department of the Navy

Contract Nonr-220(28)

\title{
STABILITY OF A CONDUCTING FLUID FLOWING
}

DOWN AN INCLINED PLANE IN A MAGNETIC FIELD

\author{
by \\ Din-Yu Hsieh
}

Reproduction in whole or in part is permitted for any purpose of the United States Government

Division of Engineering and Applied Science

California Institute of Technology

Pasadena, California 


\title{
STABILITY OF A CONDUCTING FLUID FLOWING \\ DOWN AN INCLINED PLANE IN A MAGNETIC FIELD
}

\begin{abstract}
A stability analysis is made for the laminar flow of a layer of a viscous and electrically conducting fluid down an inclined plane in a transverse magnetic field. It is found that the effect of the magnetic field, revealed through the Hartmann number, is to stabilize the flow. A simpler and physically clearer approximate treatment of the same problem based on the principle of local balance is also given. The results agree quite satisfactorily with the exact analysis.
\end{abstract}




\section{Introduction}

The stability of laminar flows of an electrically conducting fluid in a magnetic field has been studied fairly extensively. Among others, Chandrasekhar ${ }^{(1)}$ has investigated the stability of flow between coaxial rotating cylinders with a magnetic field in the axial direction, Stuart ${ }^{(2)}$ investigated the stability of pressure flow between parallel planes in a parallel magnetic field, while Lock ${ }^{(3)}$ has studied the latter stability with a magnetic field perpendicular to the direction of motion and to the boundary planes. In all these cases, it is found that the presence of magnetic fields tends to stabilize the system. In the present paper, we shall investigate the effect of a magnetic field on the stability of the gravity flow of a conducting fluid down an inclined plane. The latter stability for non-conducting fluids

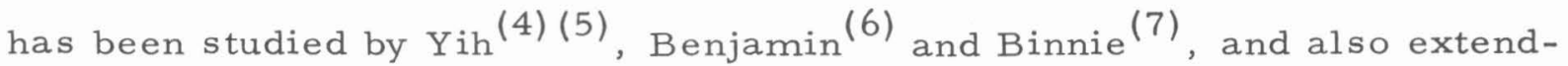
ed by the present author to the flow of superfluids ${ }^{(8)}$. It is found in general that the critical Reynolds number is quite low. From the study of the physical mechanism of this type of instability (9), it may be inferred that

(1) S. Chandrasekhar, Proc. Roy. Soc. (London) A, 216, 293 (1953).

${ }^{(2)}$ J. T. Stuart, Proc. Roy. Soc. (London) A, 221, 189 (1954).

${ }^{(3)}$ R. C. Lock, Proc. Roy. Soc. (London) A, 233, 105 (1955).

${ }^{(4)}$ C. -S. Yih, Proc. 2nd U.S. Nat. Congr. Appl. Mech. (ASME, N.Y. $1955), 623$.

(5) C.-S. Yih, Physics of Fluids, 6, 321 (1963).

(6) T. B. Benjamin, J. Fluid Mech. 2, 554 (1957).

(7) A. M. Binnie, J. Fluid Mech. 2, 551 (1957).

${ }^{(8)}$ D. Y. Hsieh, Physics of Fluids, 7, 1755(1964).

${ }^{(9)}$ M. S. Plesset and D. Y. Hsieh,( in press). 
the crucial feature is the velocity profile of the undisturbed flow. Therefore we may expect, as indeed can be verified by analysis, that a magnetic field parallel to the inclined plane will have relatively slight effects on the stability, while a transverse magnetic field may have quite pronounced

effects. This expectation is also in agreement with the results of Stuart ${ }^{(2)}$ and Lock ${ }^{(3)}$. Therefore, in the following, we shall only consider the case in which the magnetic field is in the direction perpendicular to the inclined plane.

2. The Fundamental Equations

The hydromagnetic equations for a viscous, incompressible, conducting fluids are as follows.

Maxwell's equations:

$$
\begin{aligned}
& \nabla \times \underset{w}{H}=\frac{4 \pi}{c} J_{m}, \\
& \nabla \cdot \underset{m}{H}=0, \\
& \nabla \times \underset{w}{E}=-\frac{\mu}{c} \frac{\partial H}{\partial t}, \\
& \epsilon \cdot \underline{E}=e,
\end{aligned}
$$

Ohm's law for a moving fluid:

$$
J=\sigma\left(\underline{E}+\frac{\mu}{C} \underline{v} \times \underline{H}\right),
$$

The equation of continuity:

$$
\nabla \cdot \underline{v}=0
$$

The momentum equation: 


$$
\rho \frac{\partial \underline{y}}{\partial t}+\rho(\underline{v} \cdot \nabla)_{\underline{v}}=-\nabla p+\frac{\mu}{c}(\underline{J} \times \underset{m}{H})+\eta \nabla^{2} \underline{v}-\rho \nabla \Omega
$$

and the energy equation

$$
\frac{\partial \mathrm{U}}{\partial \mathrm{t}}+(\underline{\mathrm{v}} \cdot \nabla) \mathrm{U}=\frac{\mathrm{J}^{2}}{\sigma}+\kappa \nabla^{2} \mathrm{~T}+\frac{\eta}{2} \sum_{\alpha, \beta=1}^{3}\left(\frac{\partial \mathrm{v}_{\alpha}}{\partial \mathrm{x}_{\beta}}+\frac{\partial \mathrm{v}_{\beta}}{\partial \mathrm{x}_{\alpha}}\right)^{2},
$$

where $p, \rho, T$ and $U$ are the pressure, density, temperature and internal energy of the fluid; $\boldsymbol{\epsilon}, \mu, \sigma, \boldsymbol{\eta}$ and $\kappa$ are the dielectric constant, permeability, coefficients of electrical conductivity, viscosity and thermal conductivity; $\Omega$ is the potential of the external force; and $\underset{\sim}{\mathrm{H}}, \underset{\sim}{\mathrm{J}}$ and $e$ are magnetic field, electric field, current density and charge density. In arriving at the above set of equations, we have assumed that the constitutive and transport coefficients are constant scalars, that the displacement current can be neglected in Eq. (1), that the force due to the electric field may be neglected in Eq. (7) and that the Ohm's law as stated by Eq. (5), which neglects the convection current, may be justified. We should also have the equation of state which gives the expression of $U$ in terms of $\rho$ and $T$ to complete the system. However, as it stands, Eq. (8) is not coupled with other equations; hence it can be disregarded if no information about $U$ and $T$ is desired. Likewise, Eq. (4), which is also uncoupled from the other equations, only serves to determine the charge density e.

\section{The Primary Flow}

The primary flow to be considered is a layer of fluid flowing in parallel flow on a plane making an angle $\boldsymbol{\theta}$ with the horizontal direction. An external uniform magnetic field $H$ is applied in the direction perpendicular to the plane. Let the thickness of the layer be $h$. A coordinate 
system is chosen with the origin at the free surface of the layer as shown in Fig. 1. Then $\Omega$, the potential due to the gravitational force field, will be given by

$$
\Omega=y g \cos \theta-x g \sin \theta
$$

Now let us look for such an undisturbed system that

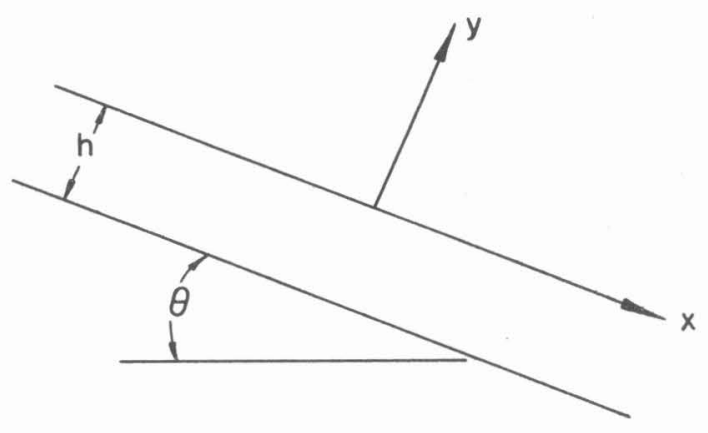

Figure 1

$$
\underline{v}=(V(y), 0,0), \quad \underset{m}{H}=(H b(y), H, 0), \quad J=(0,0, J(y)), \quad E=(0,0, E) .
$$

The electric field and current andadditional magnetic field are introduced in order to satisfy the governing equations.

Equation (5) yields

$$
J(y)=\sigma\left(E+\frac{\mu}{c} H V(y)\right)
$$

Then Eq. (7) leads to $p=p(y)$, and

$$
\eta V^{\prime \prime}-\frac{\mu H \sigma}{c}\left(E+\frac{\mu H}{c} V\right)+\rho g \sin \theta=0
$$

With the introduction of the Hartmann number $M=\frac{\mu \mathrm{Hh}}{\mathrm{c}} \sqrt{\frac{\sigma}{\eta}}$, Eq. can be written as

$$
V^{\prime \prime}-\frac{M^{2}}{h^{2}} \quad V=\frac{\mu \sigma}{c \eta} H E-\frac{\rho g}{\eta} \sin \theta .
$$

As $\mathrm{V}(-\mathrm{h})=\mathrm{V}^{\prime}(\mathrm{o})=0$, we obtain

$$
V(y)=V_{0} \frac{\cosh M-\cosh \left(M \frac{y}{h}\right)}{\cosh M-1} \text {, }
$$


where

$$
V_{0}=\frac{(\cosh M-1) h^{2}}{M^{2} \cosh M}\left(\frac{\rho g}{\eta} \quad \sin \theta-\frac{\mu \sigma}{c \eta} H E\right) .
$$

The total discharge per unit width, incidentally, is

$$
Q=\int_{-h}^{O} V(y) d y=\frac{V_{o}}{\cosh M-1}\left(h \cosh M-\frac{h}{M} \sinh M\right),
$$

while $\frac{d Q}{d h}$, if we use Eq. (14) and note the linear dependence on $h$ of $M$, is found to be

$$
\frac{d Q}{d h}=V_{0} \frac{\cosh M+1}{\cosh M}
$$

We shall require that outside the fluid layer only the applied magnetic field $(0, \mathrm{H}, 0)$ is present, and that the total flux of current in the $z$-direction is zero. The latter requirement leads to the condition

$$
\int_{-h}^{0} J(y) d y=0
$$

while the former requires that

$$
\mathrm{b}(\mathrm{o})=\mathrm{b}(-\mathrm{h})=0
$$

Equations (10), (13) and (17) then lead to

$$
E=\frac{\mu H V_{O}}{c} \frac{\sinh M-M \cosh M}{M(\cosh M-1)},
$$

and then Eq. (5) yields

$$
J(y)=\frac{\sigma \mu H V_{o}}{c} \frac{\sinh M-M \cosh \left(M \frac{y}{h}\right)}{M(\cosh M-1)} .
$$

Equation (1), with Eq. (18), then leads to 


$$
\mathrm{b}(\mathrm{y})=-\frac{4 \pi \sigma \mu \mathrm{V}_{\mathrm{o}}}{\mathrm{c}^{2}} \frac{\mathrm{y} \sinh \mathrm{M}-\mathrm{h} \sinh \left(\frac{M y}{h}\right)}{M(\cosh M-1)} .
$$

\section{The Stability Problem}

Let us superimpose a two-dimensional disturbance on the primary flow so that the elevation of the free surface is given by

$$
y=\zeta(x, t)=\zeta e^{i k(x-a t)}
$$

Thus any perturbed quantity $g(x, y, t)$ may be written as

$$
g(x, y, t)=g(y) e^{i k(x-a t)}
$$

After the system is perturbed, we have ${ }_{m}=\left(v_{x}, v+v_{y}, v_{z}\right)$, $\underset{m}{H}=\left(H b+H_{x}, H+H_{y}, H_{z}\right), \underset{m}{J}=\left(J_{x}, J_{y}, J+J_{z}\right)$ and $\underset{m}{E}=\left(E_{x}, E_{y}, E+E_{z}\right) . \quad W e$ shall assume that the disturbance is small and that the squares of the small quantities in all the equations can be neglected. Eliminating $p$ from Eq. (7) and using Eqs. (1), (2) and (6), we obtain

$$
\begin{aligned}
v_{y}^{\prime v} & -2 k^{2} v_{y}^{\prime \prime}+k^{4} v_{y}-i k \frac{\rho}{\eta}\left[(v-a)\left(v_{y}^{\prime \prime}-k^{2} v_{y}\right)-v^{\prime \prime} v_{y}\right] \\
= & \frac{i k \mu H}{4 \pi \eta}\left[\frac{i}{k}\left(H_{y}^{\prime \prime \prime}-k^{2} H_{y}^{\prime}\right)-b\left(H_{y}^{\prime \prime}-k^{2} H_{y}\right)+b^{\prime \prime} H_{y}\right] .
\end{aligned}
$$

We can make the above equation non-dimensional by taking $v_{\mathrm{y}}=\mathrm{V}_{\mathrm{o}} \psi$, $\mathrm{H}_{\mathrm{y}}=\mathrm{H} \varphi, \mathrm{V}=\mathrm{V}_{\mathrm{o}} \overline{\mathrm{V}}, \mathrm{a}=\mathrm{V}_{\mathrm{o}} \overline{\mathrm{a}}, \mathrm{k}=\frac{\overline{\mathrm{k}}}{\mathrm{h}}$ and $\mathrm{y}=\mathrm{h} \overline{\mathrm{y}}$, and substitute them into the equation. Dropping bars of the newly introduced quantities to simplify writing, we find that Eq. (24) becomes 


$$
\begin{aligned}
& {\left[\psi^{\prime V}-2 k^{2} \psi^{\prime \prime}+k^{4} \psi\right]-i k R\left[(V-a)\left(\psi^{\prime \prime}-k^{2} \psi\right)-V^{\prime \prime} \psi\right]} \\
& =-\frac{M^{2}}{\mathrm{R}_{M}}\left[\varphi^{\prime \prime \prime}-k^{2} \varphi^{\prime}+i k b\left(\psi^{\prime \prime}-k^{2} \varphi\right)+i k b " \varphi\right],
\end{aligned}
$$

where

$$
\mathrm{R}=\frac{\mathrm{V}_{\mathrm{o}} \rho \mathrm{h}}{\eta},
$$

and

$$
R_{M}=\frac{4 \pi \mu \sigma V_{0} h}{c^{2}}
$$

$R$ and $R_{M}$ are called the Reynolds number and magnetic Reynolds number respectively. Eliminating $\mathrm{J}_{\mathrm{z}}$ from Eqs. (1) and (5), and using Eqs. (2) and (3), we obtain similarly:

$$
\varphi^{\prime \prime}-k^{2} \varphi=-R_{M}\left[\psi^{\prime}+i k b \psi-i k(V-a) \varphi\right] .
$$

The electromagnetic fields in regions outside the fluid layer are governed by the Maxwell equations. With the space and time variation given by Eq. (23), the field quantities can be readily determined for a medium which is conducting or non-conducting.

The boundary conditions will contain the following features.

(i) The normal velocity of the fluid vanishes at the bottom:

$$
\psi(-1)=0
$$

(ii) The tangential velocity of the fluid vanishes at the bottom:

$$
\psi^{\prime}(-1)=0 \text {, }
$$

after use of Eq. (6). 
(iii) The shearing stress vanishes at the free surface;

$$
\frac{\partial}{\partial x}\left(v_{y}\right)+\frac{\partial}{\partial y}\left(v+v_{x}\right)=0 \quad \text { on } \quad y=\zeta(x, t) \quad ;
$$

or

$$
\psi^{\prime \prime}(0)+k^{2} \psi(0)+\frac{i k M^{2}}{\cosh M-1} \zeta=0 .
$$

(iv) The normal stress is continuous across the free surface:

$$
\mathrm{p}=2 \eta\left(\frac{\partial \mathrm{v}}{\partial \mathrm{y}}\right)-\Gamma \rho\left(\frac{\partial^{2} \zeta}{\partial \mathrm{x}^{2}}\right)+\rho g \cos \theta \zeta, \text { at } \quad \mathrm{y}=0 \text {, }
$$

where $\rho \Gamma$ is the surface tension coefficient. Using Eq. (7), we then obtain

$$
\begin{gathered}
\left(\psi^{\prime \prime \prime}-\mathrm{k}^{2} \psi^{\prime}\right)+\frac{\mathrm{M}^{2}}{\mathrm{R}_{\mathrm{M}}}\left(\varphi^{\prime \prime}-\mathrm{k}^{2} \varphi\right)-\mathrm{ik}\left\{\mathrm{R}\left[(\mathrm{V}-\mathrm{a}) \psi^{\prime}-\mathrm{V}^{\prime} \psi\right]+\frac{\mathrm{M}^{2}}{\mathrm{R}_{\mathrm{M}}} \mathrm{b}^{\prime} \varphi\right\} \\
=2 \mathrm{k}^{2} \psi^{\prime}+\mathrm{k}^{2}\left(\Gamma \mathrm{k}^{2} \mathrm{R}+\frac{\mathrm{M} \sinh \mathrm{M}}{\cosh \mathrm{M}-1} \cot \theta\right) \zeta \text {, at } \mathrm{y}=0,
\end{gathered}
$$

where the relation $V_{0}=\frac{\rho g \sin \theta h^{2}}{\eta} \frac{\cosh M-1}{M \sinh M}$ which is derivable from Eqs. (14) and (19) has been used.

(v) The free surface will satisfy the kinematic surface condition:

$$
\psi(0)-i k\left(V_{0}-a\right) \zeta=0
$$

(vi) The electromagnetic fields in the fluid layer will be appropriately connected to those in the free space above and those in the material wall below.

\section{Solution for Long Waves}

In the analysis of the stability problem for non-conducting fluids (5), it is shown that the criterion for stability is essentially determined by the 
disturbances of long wavelength. We expect this feature to remain true so long as the magnetic field is not too strong. When the wavelength of the disturbance is long compared with the depth of the fluid layer, i.e., when $\mathrm{k}<<1$, a scheme of successive approximation can be developed. For the first approximation, we shall neglect all quantities of order $O(k)$ in the system of differential equations and boundary conditions. Then Eqs. (25) and (28) become

$$
\psi_{O}^{\prime v}+\frac{M^{2}}{R_{M}} \varphi_{O}^{\prime \prime \prime}=0 \text {, }
$$

and

$$
\varphi_{\mathrm{O}}^{\prime \prime}+\mathrm{R}_{\mathrm{M}_{\mathrm{O}}}^{\prime}{ }^{\prime}=0,
$$

and the boundary conditions become

$$
\begin{array}{ll}
\text { (i) } & \psi_{0}(-1)=0, \\
\text { (ii) } & \psi_{0}^{\prime}(-1)=0, \\
\text { (iii) } & \psi_{0}^{\prime \prime}(0)+\frac{M^{2}}{\cosh M-1} \text { ik } \xi_{0}=0, \\
\text { (iv) } & \psi_{0}^{\prime \prime \prime}(0)+\frac{M^{2}}{R_{M}} \varphi_{O}^{\prime \prime}(0)=0,
\end{array}
$$

and

$$
\text { (v) } \quad \psi_{0}(o)-\left(V_{0}-a_{0}\right) i k \xi_{0}=0 \text {, }
$$

where the subscript zero signifies that it is the solution for the first approximation.

Equations (34) and (35) lead to

$$
\psi_{0}^{\prime v}-M^{2} \psi_{O}^{\prime \prime}=0
$$

Thus the general solution is 


$$
\psi_{0}=A_{0} \cosh M y+B_{0} \sinh M_{y}+C_{0} y+D_{0} .
$$

Now Eq. (39), with application of Eq. (35), becomes

$$
\psi_{0}^{\prime \prime \prime}(0)-M^{2} \psi^{\prime}(0)=0
$$

which requires

$$
C_{0}=0
$$

Then Eqs. (36) and (37) lead to

$$
\psi_{0}=A_{0}[\cosh M(1+y)-1] .
$$

From Eq. (38), we get

$$
i k \zeta_{0}=-A_{0} \cosh M(\cosh M-1),
$$

and from Eq. (40), as $\mathrm{V}_{\mathrm{O}}=1$, we obtain

$$
a_{0}=\frac{\cosh M+1}{\cosh M}
$$

It may be noted that $a_{0}$ is identical with the expression of $\frac{d Q}{d h}$ given by Eq. (16) .

The general expression for $\varphi_{\mathrm{O}}$ can be written down immediately from Eq. (35):

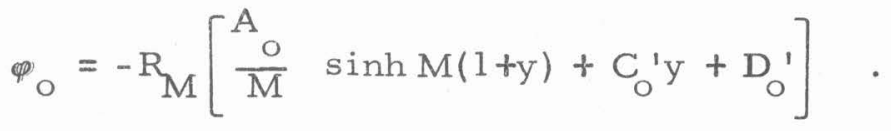

The coefficients $\mathrm{C}_{\mathrm{O}}^{\prime}$ and $\mathrm{D}_{\mathrm{O}}^{\prime}$ can be readily determined, by the application of the boundary conditions (vi). Now for almost all conducting liquid of interest, the ratio $\frac{R_{M}}{R}$ is extremely small. For mercury, it is about $1.5 \times 10^{-7}$, while for liquid sodium, it is $7.5 \times 10^{-6}$. Therefore in the range of Reynolds number usually encountered in laminar flow, $R_{M}$ is 
very small. The value of $\varphi_{0}$, as may be seen easily, is in general of the order $O\left(R_{M}\right)$. Hence, as far as the stability of the flow is concerned, there is practically no need to obtain the explicit expression for $\boldsymbol{\varphi}_{0}$. For the next approximation, we shall take $\psi=\psi_{0}+\psi_{1}$, where $\psi_{1}=O(k)$, etc., and neglect all terms that are quadratic in $k$ in the differential equations and boundary conditions. Keeping in mind that $\varphi_{\mathrm{O}}=\mathrm{O}\left(\mathrm{R}_{\mathrm{M}}\right)$ and $\mathrm{b}=\mathrm{O}\left(\mathrm{R}_{\mathrm{M}}\right)$, we obtain from Eqs. (25) and (28):

$$
\psi_{1}^{\prime v}-M^{2} \psi_{1}^{\prime \prime}=\operatorname{ik}\left\{R\left[\left(V-a_{O}\right) \psi_{O}^{\prime \prime}-V^{\prime \prime} \psi_{O}\right]+O\left(R_{M}\right)\right\} .
$$

As

$$
V=\frac{\cosh M-\cosh M y}{\cosh M-1}, \quad V^{\prime \prime}=-\frac{M^{2} \cosh M y}{\cosh M-1},
$$

thus with $\mathrm{A}_{\mathrm{O}}=1$, Eq. (47) becomes

$$
\psi_{1}^{\prime v}-M^{2} \psi_{1}^{\prime \prime}=i k R \frac{M^{2} \tanh M \sinh M y}{\cosh M-1}
$$

The general solution of the above equation is:

$$
\Psi_{1}=A_{1} \cosh M y+B_{1} \sinh M y+C_{1} y+D_{1}+\frac{i k R}{2 M} \frac{\tanh M}{\cosh M-1} y \cosh M y
$$

Now, from Eq. (28), we obtain:

$$
\varphi_{1}^{\prime \prime}+\mathrm{R}_{M_{1}}^{\psi_{1}^{\prime}}=\mathrm{O}\left(\mathrm{R}_{M}^{2}\right)
$$

Thus in particular,

$$
\varphi_{1}^{\prime \prime}(0)=-R_{M}\left(B_{1} M+C_{1}+\frac{i k R}{2 M} \frac{\tanh M}{\cosh M-T}\right) .
$$

The boundary condition (iv) becomes 


$$
\begin{aligned}
& \psi_{1}^{\prime \prime \prime}(0)+\frac{M^{2}}{R_{M}} \boldsymbol{\varphi}_{1}^{\prime \prime}(0)=i k\left\{R\left[\left(V_{0}-a_{0}\right) \psi_{0}^{\prime}(0)-V^{\prime}(0) \psi_{0}(0)\right]\right. \\
& \left.-i k \zeta_{O}\left[\Gamma k^{2} R+\frac{M \sinh M}{\cosh M-1} \cot \theta\right]+O\left(R_{M}\right)\right\} \text {. }
\end{aligned}
$$

Then Eqs. (49) and (51) together with the first order solutions lead to

$$
C_{1}=i k\left\{R \frac{\sinh M}{M(\cosh M-1)}-\frac{\cosh M}{M^{2}}\left[M \sinh M \cot \theta+\Gamma k^{2} R(\cosh M-1)\right]\right\} .
$$

Boundary conditions (i) and (ii) yield

$$
A_{1} \cosh M-B_{1} \sinh M-C_{1}+D_{1}=\frac{i k R}{2 M} \frac{\sinh M}{\cosh M-1},
$$

and

$-A_{1} M \sinh M+B_{1} M \cosh M+C_{1}=-\frac{i k R}{2 M} \frac{\tanh M(\cosh M+M \sinh M)}{\cosh M-1}$, (55)

while boundary conditions (iii) and (v) are

$$
\psi_{1} "(0)+\frac{\mathrm{M}^{2}}{\cosh \mathrm{M}-1} \mathrm{ik} \zeta_{1}=0,
$$

and

$$
\psi_{1}(0)-i k \zeta_{1}\left(V_{0}-a_{0}\right)+i k \zeta_{0} a_{1}=0,
$$

and they combine to give

$$
a_{1}=\frac{A_{1}+D_{1} \cosh M}{\cosh ^{2} M(\cosh M-1)}
$$

Multiply Eq. (54)by $\cosh M, E q$. (55) by $\frac{\sinh M}{M}$, and then add to obtain

$$
A_{1}+D_{1} \cosh M=C_{1}\left(\cosh M-\frac{\sinh M}{M}\right)+\frac{i k R \sinh M}{2 M(\cosh M-1)}\left[\cosh M-\frac{\sinh M}{M}-\frac{\sinh ^{2} M}{\cosh M}\right]
$$


Using Eq. (53), we then arrive at:

$$
\begin{gathered}
a_{1}=\frac{i k}{\cosh ^{2} M(\cosh M-1)}\left\{R \frac{\tanh M}{2 M(\cosh M-1)}\left(3 \cosh ^{2} M-\frac{3 \cosh M \sinh M}{M}-\sinh ^{2} M\right)\right. \\
\left.-\frac{\cosh M}{M^{2}}\left(\cosh M-\frac{\sinh M}{M}\right)\left[M \sinh M \cot \theta+(\cosh M-1) \Gamma k^{2} R\right]\right\} .
\end{gathered}
$$

\section{Stability Criterions}

The flow system is stable or unstable according as the imaginary part of $a=a_{0}+a_{1}$ is positive or negative. For this problem, $a_{0}$ is real, while $a_{y}$ is imaginary; therefore, the stability criterion is determined by the sign of $a_{1}$.

It may be seen from the expression of $a_{1}$, that coefficients associated with $\Gamma$ and $\cot \theta$ are all negative; this means that surface tension always tends to stabilize the flow while gravity will tend to stabilize or distabilize the system according to whether the fluid is flowing down the upperside or the underside of the plane.

If we neglect the effect of surface tension, we may conclude that the flow is stable if

$$
\mathrm{R}<\mathrm{F}(\mathrm{M}) \cot \theta
$$

where

$$
F(M)=\frac{2 \cosh ^{2} M\left(\cosh M-\frac{\sinh M}{M}\right)(\cosh M-1)}{3 \cosh ^{2} M-\frac{3 \cosh M \sinh M}{M}-\sinh ^{2} M} .
$$

$F(M)$ is a monotonically increasing function and as a function of $M$ is shown in Fig. 2. Thus we may conclude that the magnetic field tends to 
stabilize the flow system. As $\mathbf{M} \rightarrow 0$, it may be readily verified that $F(M) \rightarrow \frac{5}{4}$, thus the results agree with those of $Y_{i h}^{(5)}$ and Benjamin ${ }^{(6)}$. For large $M$,

$$
F(M) \approx \frac{M-1}{2(2 M-3)} e^{2 M}
$$

The above result will not hold for very large $M$, since in that case, the stability will be most likely controlled by the shear wave disturbance rather than these soft waves ${ }^{(5)}$, while Lock ${ }^{(3)}$ has shown that the critical Reynolds number for the former type of disturbance in his problem is only linearly proportional to $M$ for large $M$.

\section{Simple Description of the Stability Problem}

The principle of local balance ${ }^{(10)}$ has been extended to the stability problem of laminar flow down an inclined plane (9). That approach offers a much simpler analysis and clearer physical picture while it retains satisfying accuracy. We shall also apply that principle to this problem.

Once the primary flow is obtained, the speed of propagation of disturbances of long wavelength, a, may be immediately written down from the total discharge as expressed in Eq. (16) ${ }^{(11)}$. Thus

$$
a_{0}=\frac{d Q}{d h}=V_{0} \frac{\cosh M+1}{\cosh M} \text {. }
$$

Let us now transform the coordinate system from the original $(\mathrm{x}, \mathrm{y})$ to a new coordinate system $\left(x^{\prime}, y\right)$ by the Galilean transformation:

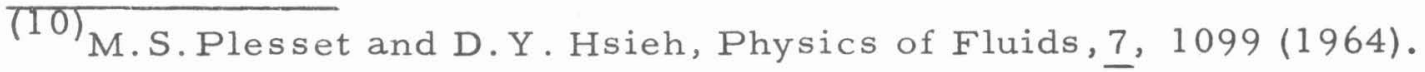

(11) M.J. Lighthill and G.B. Whitham, Proc. Roy.Soc. A, 229, 281 (1955). 


$$
x^{\prime}=x-a_{0} t, \quad y^{\prime}=y,
$$

which brings the wave disturbance of the free surface to rest. In this new frame of reference, the disturbance wave is given by

$$
y=\zeta e^{i k x^{\prime}},
$$

or, taking the imaginary part:

$$
\mathrm{y}=\zeta \sin \mathrm{kx}^{\prime}
$$

Also in the new frame, the fluid in the layer is moving with velocity:

$$
U(y)=V(y)-a_{O}=V_{0} \frac{1-\cosh M \cosh (M y / h)}{\cosh M(\cosh M-1)} .
$$

We now compute the pressure exerted on the "wavy wall" (Eq. (66')) by a layer of incompressible inviscid fluid bounded by a rigid wall at $\mathrm{y}=-\mathrm{h}$, with primary velocity given by Eq. (67). Let the fluid velocity in the presence of a wavy wall be given by $(U+u, v)$, then the momentum and continuity equation for steady flow are

$$
\begin{aligned}
& (U+u) \frac{\partial u}{\partial x}+v \frac{\partial}{\partial y}(U+u)=-\frac{1}{\rho} \frac{\partial p}{\partial x}, \\
& (U+u) \frac{\partial v}{\partial x}+v \frac{\partial v}{\partial y}=-\frac{1}{\rho} \frac{\partial p}{\partial y},
\end{aligned}
$$

and

$$
\frac{\partial u}{\partial x}+\frac{\partial v}{\partial y}=0
$$

We eliminate $\mathrm{p}$ and $\mathrm{u}$ and neglect quadratic terms in $\mathrm{u}$ and $\mathrm{v}$, and get

$$
\frac{\partial^{2} v}{\partial y^{2}}+\frac{\partial^{2} v}{\partial x^{2}}-\frac{U^{\prime \prime}}{U} v=0
$$


Now let

$$
v(x, y)=f(y) \cos k x
$$

Then Eq. (71) becomes

$$
f^{\prime \prime}-\left(\frac{U^{\prime \prime}}{U}+k^{2}\right) f=0
$$

For long wavelength disturbance, we have $\mathrm{kh} \ll 1$, thus we may approximate Eq. (73) by

$$
f^{\prime \prime}-\frac{U^{\prime \prime}}{U} \quad f=0
$$

One solution of the last equation is $U$, then by reduction of order, we obtain the general solution of Eq. (74):

$$
f=A U(y)+B U(y) \int_{0}^{y} \frac{d y^{\prime}}{U^{2}\left(y^{\prime}\right)} \text {. }
$$

The boundary conditions at the wavy surface and the bottom require that:

$$
f=0 \quad \text { at } \quad y=-h \quad \text {, }
$$

and

$$
f=U_{0} k \zeta \quad \text { at } \quad y=0 \text {, }
$$

where

$$
\mathrm{U}_{\mathrm{O}}=\mathrm{U}(0)
$$

Thus

$$
f=k \zeta\left[U(y)+\frac{U(y)}{G} \int_{0}^{y} \frac{d y^{\prime}}{U^{2}\left(y^{\prime}\right)}\right] .
$$

where

$$
G=\int_{0}^{h} \frac{d y}{U^{2}(y)} .
$$


For this case, as $U^{\prime}(0)=0$, the pressure applied to the wavy wall is readily seen from Eqs. (68) and (70) to be:

$$
p(o)=\frac{\rho U_{0} f^{\prime}(0)}{k} \sin k x
$$

As

$$
f^{\prime}(y)=k \zeta\left[U^{\prime}(y)+\frac{U^{\prime}(y)}{G} \int_{0}^{y} \frac{d y^{\prime}}{U^{2}\left(y^{\prime}\right)}+\frac{1}{G U(y)}\right],
$$

we obtain

$$
p(0)=\frac{\rho \zeta}{G} \sin k x .
$$

This pressure is counterbalanced by the gravitational restoring force $\rho g \cos \theta \zeta \sin k x$ in the stability problem, (cf. Fig.l), hence the critical condition for stability may be expressed by

$$
g \cos \theta=\frac{1}{G} \text {. }
$$

Now

$$
\begin{aligned}
G & =\int_{0}^{h} \frac{d y}{U^{2}(y)}=\frac{\cosh ^{2} M(\cosh M-1)^{2}}{V_{0}^{2}} \int_{0}^{h} \frac{d y}{\left(\cosh M \cosh M \frac{y}{h}-1\right)^{2}} \\
& =\frac{\cosh ^{2} M(\cosh M-1)^{2} h}{V_{0}{ }^{2} M} \int_{0}^{M} \frac{d z}{(\cosh M \cosh z-1)^{2}} .
\end{aligned}
$$

The integral is readily integrated and we obtain

$$
\frac{1}{G}=\frac{V_{0}{ }^{2} M}{\cosh ^{2} M(\cosh M-1)^{2} h} \frac{\sinh ^{3} M}{\cosh M+\pi / 2} .
$$

As in the derivation of Eq. (32) we can now express

$$
g \cos \theta=\frac{V_{0} \eta \cot \theta}{\rho h^{2}} \frac{M \sinh M}{\cosh M-1} \text {. }
$$


Then Eq. (82) may be expressed as

$$
\frac{V_{0} \eta \cot \theta}{\rho h^{2}} \frac{M \sinh M}{\cosh M-1}=\frac{V_{0}^{2} M \sinh ^{3} M}{h \cosh ^{2} M(\cosh M-1)^{2}(\cosh M+\pi / 2)}
$$

or

$$
F^{\prime}(M) \cot \theta=R,
$$

where

$$
F^{\prime}(M)=\frac{\cosh ^{2} M(\cosh M-1)(\cosh M+\pi / 2)}{\sinh ^{2} M} .
$$

The comparison between $F(M)$ and $F^{\prime}(M)$ is shown in Fig. 2. The general agreement between $F$ and $F^{\prime}$ over all values of $M$ shows that the above simple description reveals the essential physical mechanism of the instability. 


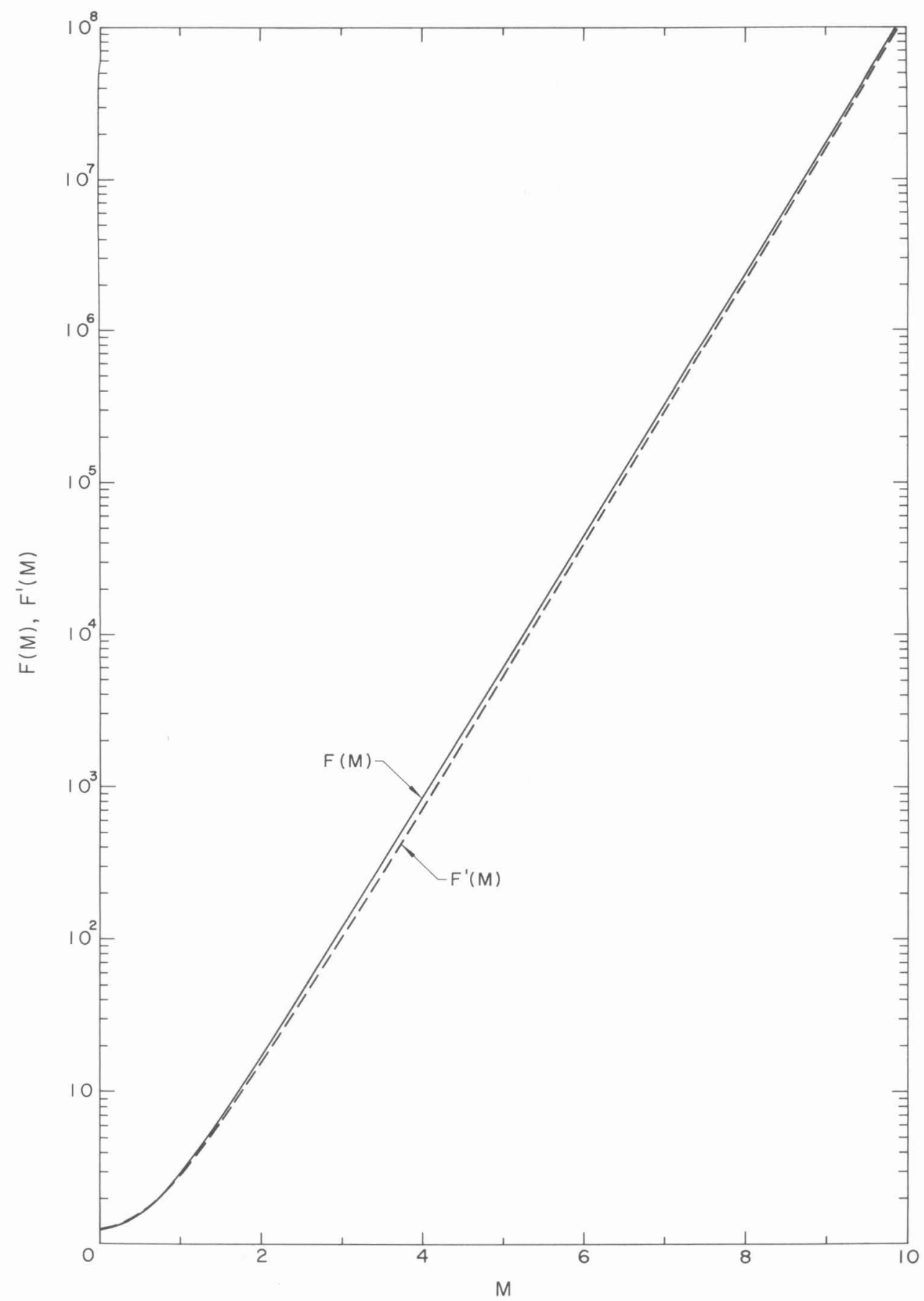

Figure 2. Comparison of the critical values of $R / \cot \theta$, as a function of the Hartmann number $M$, where $R$ is the Reynolds number, and $\theta$ is the angle of inclination of the plane; $F$ is the value for this ratio obtained from the complete theory, and $F^{\prime}$ is that obtained from the approximate theory of local balance. 


\section{DISTRIBUTION LIST FOR UNCLAŚSIFIED TECHNICAL REPORTS ISSUED UNDER}

Contract Nonr-220(28) Task Nr 062-059

Single Copies Unless Otherwise Given

Chief of Naval Research Dept. of the Navy

Washington 25, D. C.

Attn: Codes 438 (3)

461

463

429

Commanding Officer

Office of Naval Research

Branch Office

495 Summer Street

Boston 10, Mass.

Commanding Officer

Office of Naval Research

Branch Office

230 No. Michigan Ave.

Chicago 1, Illinois

Commanding Officer

Office of Naval Research

Branch Office

207 West 24th Street

New York 11, New York

Commanding Officer

Office of Naval Research

Branch Office

1030 East Green Street

Pasadena 1, Calif.

Commanding Officer

Office of Naval Research

Branch Office

Navy No. 100, Box 39

Fleet Post Office

New York, New York

Commanding Officer

Office of Naval Research

Branch Office

1000 Geary Street

San Francisco 9, California

Director

Naval Research Laboratory Washington 25, D. C.

Attn: Codes 2000

2020

2027

Chief, Bur. of Yards and Docks

Department of the Navy

Washington 25, D.C.

Attn: Codes D-202

$D-400$

D- 500
Chief, Bureau of Ships

Department of the Navy

Washington 25, D.C.

Attn: Codes 300

305

335

341

$342 \mathrm{~A}$

345

421

440

442

$634 \mathrm{~A}$

Chief, Bur. of Naval Weapons

Department of the Navy

Washington 25, D.C.

Attn: Codes $\mathrm{R}$

R-12
RR
RRRE
RU
RUTO

Commanding Off. and Director Fort Trumbull

David Taylor Model Basin New London, Conn.

Washington 7, D.C.

Attn: Codes 142

500

513

521

526

550

563

589

Commander

Naval Ordnance Laboratory Naval Electronic Lab.

Silver Spring, Maryland

Attn: Dr. A. May

Desk DA

Desk HL

Desk DR

Commander

Naval Ordnance Test Station

China Lake, Calif.

Attn: Mr. J.W. Hicks

Codes 5014

4032

753

Superintendent

U.S. Naval Academy

Annapolis, Maryland

Attn: Library
Hydrographer

U.S. Navy Hydrographic Off. Washington, 25, D.C.

Commanding Off. and Dir.

U. S. Navy Engineering

Laboratory

Annapolis, Maryland

Attn: Code 750

Commander

U. S. Naval Weapons Lab.

Dahlgren, Virginia

Attn: Technical Library Div. Computation and Exterior Ballistics Lab. (Dr. Hershey)

Commanding Officer NROTC and Naval Adm. Unit Massachusetts Inst. of Tech. Cambridge 39, Mass.

Commanding Off. and Dir. Underwater Sound Laboratory

Attn: Technical Library

Commanding Off. and Dir. U.S. Navy Mine Def. Lab. Panama City, Florida

Superintendent

U.S. Naval Postgrad.School

Monterey, California

Attn: Library

Commanding Off. and Dir.

San Diego 52, California

Attn: Code 4223

Commanding Off. and Dir. U.S. Naval Civil Eng. Lab. Port Hueneme, California

Mr. C. K. Chatten

Code 949

New York Naval Shipyard

Material Laboratory

B rooklyn 1, New York

Commander

Norfolk Naval Shipyard

Portsmouth, Virginia 
Commander

U.S. Naval Ord. Test Sta.

Pasadena Annex

3202 E. Foothill Blvd.

Pasadena, Calif.

Attn: Mr. J.W.Hoyt

Research Division P 508

$\mathrm{P} 804$

$\mathrm{P} 807$

P80962 (Library Sec)

Commander

New York Naval Shipyard

Naval Base

B rooklyn, New York

Commander

Boston Naval Shipyard

Boston 29, Mass.

Commander

Philadelphia Naval Shipyard Fort Belvoir, Virginia

Naval Base

Philadelphia 12, Penn.

Commander

Portsmouth Naval Shipyard Dept. of Commerce

Portsmouth, N. H

Attn: Design Division

Commander

Charleston Naval Shipyard

U.S. Naval Base

Charleston, S. C.

Commanding Officer

U.S. Naval Underwate

Newport, Rhode Island

Attn: Research Division

Commander

Long Beach Naval Shipyard Fluid Mechanics Section

Long Beach 2, Calif.

Commander

National Bureau of Standards

Washington 25, D.C.

Attn: Dr. G.B.Schubauer

Pearl Harbor Naval Shipyard

Navy No. 128, Fleet Post Off.

San Francisco, Calif.

Commander

San Francisco Naval Shipyard

San Francisco 24, Calif.

Commander

Mare Island Naval Shipyard

Vallejo, Calif.

Superintendent

U.S. Merchant Marine Academy

Kings Point

Long Island, New York

Attn: Dept. of Engineering
U.S. Atomic Energy

Commission

Tech. Infor. Ser. Ext.

P.O. Box 62

Oakridge, Tenn.

Director of Research

National Aero. and Space Admplied Physics Laboratory

8621 Georgia Avenue

Silver Spring, Maryland

washington 25 ,

Director

Langley Research Ctr. New York State University

National Aero and

Space Adm.

Langley Field, Va. Baltimore 18, Maryland

Attn: Prof. S. Corrsin Prof. F. H. Clauser Prof. O. M. Phillips

Maritime College

Engineering Department Fort Schuyler, New York
National Aero and Space Adm.

Moffett Field, Calif.

Director

Lewis Research Center

National Aero and Space Adm.

Cleveland, Ohio

Engineering Science Division National Science Foundation Washington, D. C.

Air Force Cambridge Res. Ctr. 230 Albany Street

Cambridge 39, Mass.

Attn: Geophysical Res. Library

Air Force Off. of Sci. Res.

Mechanics Division

Washington 25, D.C

Montreal Road

Ottawa 2, Canada

Attn: Mr. E.S.Turner

Engineering Societies Library

29 West 39th Street

New York 18, N. Y.

Society of Naval Architects and

New York 6, N. Y.

Webb Inst. of Naval Architecture Glen Cove, Long Island, N. Y. Attn: Prof. E. V. Lewis

The Johns Hopkins University Attn: Prof. J. J. Foody 
California Inst. of Tech. Pasadena, California

Attn: Hydrodynamics Lab. Prof. T. Y. Wu Prof. A. Ellis Prof. A. Acosta

University of California Berkeley 4, California Attn: Dept. of Eng. Prof. H. A. Schade Brown University Prof. J. Jovidence 12 , R. I. Prof. J. Johnson Attn: Dr. R. E. Meyer Prof E. D . W. H. Reid Prof. P. Lieber Prof. M. Holt

University of California Los Angeles, California Attn: Prof. R. W. Leonard Prof. A. Powell

Stevens Inst. of Tech. Davidson Laboratory Hoboken, New Jersey

Attn: Mr. D.Savitsky Mr. J.P.Breslin Dr. D. N.Hu Dr. S.J. Lukasik

Director

Scripps Inst. of Oceanography

University of California Director

La Jolla, California Woods Hole Oceanographic

Iowa Inst. of Hydraulic Res. Institute State University of Iowa

Iowa City, Iowa

Attn: Prof. H.Rouse Alden Hydraulic Lab. Prof. L. Landweber Worcester Poly. Inst. Prof. P.G. Hubbard Worcester, Mass.

Harvard University

Stanford University

Cambridge 38, Mass.

Stanford, California

Attn: Prof. G. Birkhoff Attn: Dr.Byrne Perry Prof. S. Goldstein

Prof.P. Garabedian

University of Michigan

Ann Arbor, Michigan

Attn: Engineering Res. Inst.

Mr. L.I.Schiff

Dr.S.Kline

Prof.E.Y. Hsu

Director

Ordnance Research Lab.

Pennsylvania State Univ.

University Park, Penn.

Department of Theoretical and Applied Mechanics

College of Engineering

University of Illinois

Urbana, Illinois

Attn: Dr. G.F. Wislicenus

Director

St. Anthony Falls Hyd. Lab.

University of Minnesota

Minneapolis 14, Minn.

Attn: Mr. J.N. Wetzel

Prof. B. Silberman Southwest Research Inst.

Prof. L.G. Straub 8500 Culebra Road

San Antonio 6, Texas

Massachusetts Inst. of Tech.

Cambridge 39, Mass.

Attn: Prof. P. Mandel

Attn: Dr.H.N.Abramson

Dept. of Aero. Engineering

University of Colorado

Prof. M.A. Abkowitz Boulder, Colorado

Attn: Prof. M.S. Uberoi
Hamburgische Schiffbau-

Versuchsanstalt

Bramfelder Strasse 164

Hamburg 33, Germany

Attn: Dr. O. Grim

Max-Planck Institut fur Stromungsforschung

Bottingerstrasse 6-8

Gottingen, Germany

Attn: Dr.H.Reichardt, Dir.

Prof.Dr.-Ing.S. Schuster, Baudirector

Versuchsanstalt fur Wasserbau und Schiffbau

Berlin, Germany

Netherlands Ship Model Basin

Wageningen, The Netherlands

Attn: Ir.R. Wereldsma

Dr.J.B. vanManen

Mitsubishi Shipbuilding and

Engineering Company

Nagasaki, Japan

Attn: Dr. K. Taniguchi

Mr. W. R. Wiberg, Chief

Marine Performance Staff

The Boeing Company

Aero-Space Division

P. O. Box 3707

Seattle 24, Washington

Mr. William P. Carl

Grumman Aircraft Corp.

Bethpage, Long Island

New York

Mr. G. W. Paper

ASW and Ocean Systems Dept.

Lockheed Aircraft Corp.

Burbank, California

Dr. A. Ritter

Therm Advanced Res. Div.

Therm, Incorporated

Ithaca, New York

Hydronautics, Incorporation Pindell School Road

Howard County

Laurel, Maryland

Attn: Mr.P.Eisenberg, Pres. Mr.M.P.Tulin, V.P.

Dr. J. Kotik

Technical Research Group, Inc.

Route 110

Melville, New York

AiResearch Mfg. Company 9851-9951 Sepulveda Blvd.

Los Angeles 45, Calif.

Attn: Blaine R. Parkin 
Hydrodynamics Laboratory

Convair

San Diego 12, California

Attn: Mr. H. E. Brooke Mr. R. H. Oversmith

Baker Manufacturing Company

Evansville, Wisconsin

Gibbs and Cox, Inc.

21 West Street

New York 16, New York

Electric Boat Division

General Dynamics Corp.

Groton, Connecticut

Attn: Mr. R. McCandliss

Armour Research Foundation

Illinois Inst. of $\mathrm{Tech}$.

Chicago 16, Illinois

Attn: Library

Missile Development Div.

North Amer. Aviation, Inc.

Downey, California

Attn: Dr.E.R. Van Driest

National Physical Laboratory

Teddington, Middlesex, England

Attn: Head Aerodynamics Division

Mr. A. Silverleaf

Aerojet General Corporation

6352 Irwindale Ave.

Azusa, California

Attn: Mr. C.A. Gongwer

Astropower, Inc.

2121 Paularino Ave.

Newport Beach, Calif.

Attn: R.D.Bowerman

Transportation Tech. Res. Inst.

No. 1057-1-Chome

Mejiro-machi, Toshima-ku

Tokyo-to, Japan

Oceanics, Incorporated

Plainview, Jong Island, N.Y .

Attn: Dr. Paul Kaplan

Prof. C. S. Yih

University of $\mathrm{Michigan}$

Ann Arbor, Michigan

Grumman Aircraft Corp.

Bethpage, Long Island, N.Y.

Attn: Eng. Lib, Plant 5

Mr. Leo Geyer
Professor J. William Holl

Garfield Thomas Water Tunnel

Ordnance Research Laboratory

The Pennsylvania State Univ.

P. O. Box 30

State College, Penn.

Professor George Carrier

Harvard University

Cambridge 38, Mass.

Dr. E. R. G. Eckert

Mechanical Eng. Dept.

University of Minnesota

Minneapolis, Minn. 55455 


\section{DOCUMENT CONTROL DATA - R\&D}

(Security classification of title, body of abstract and indexing annotation must be entered when the overall report is classified) 1. ORIGINATIN G ACTIVITY (Corporate author)

California Institute of Technology

Division of Engineering and Applied Science 2a. REPORT SECURITY CLASSIFICATION UNCLASSIFIED

2b. GROUP Not Applicable

3. REPORT TITLE

STABIIITY OF A CONDUCTING FLUID FIOWING DOWN AN INCIINED

PLANE IN A MAGNETIC FIELD

4. DESCRIPTIVE NOTES (Type of report and inclusive datos)

Technical Report

5. AUTHOR(S) (Last name, first name, initial)

Hsieh, Din-Yu

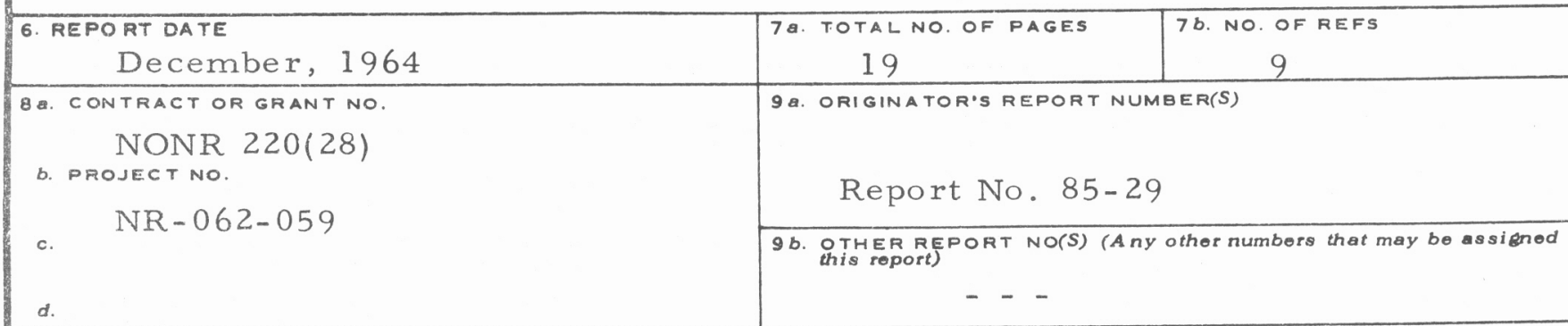

10. AVAILABILITY/LIMITATION NOTICES

Qualified requesters may obtain copies of this report from DDC.

11. SUPPL EMENTARY $A$ JTES

12. SPONSORING MILITARY ACTIVITY

Office of Naval Research

13. ABSTRACT

A stability analysis is made for the laminar flow of a layer of a viscous and electrically conducting fluid down an inclined plane in a transverse magnetic field. It is found that the effect of the magnetic field, revealed through the Hartmann number, is to stabilize the flow. A simpler and physically clearer approximate treatment of the same problem based on the principle of local balance is also given. The results agree quite satisfactorily with the exact analysis. 


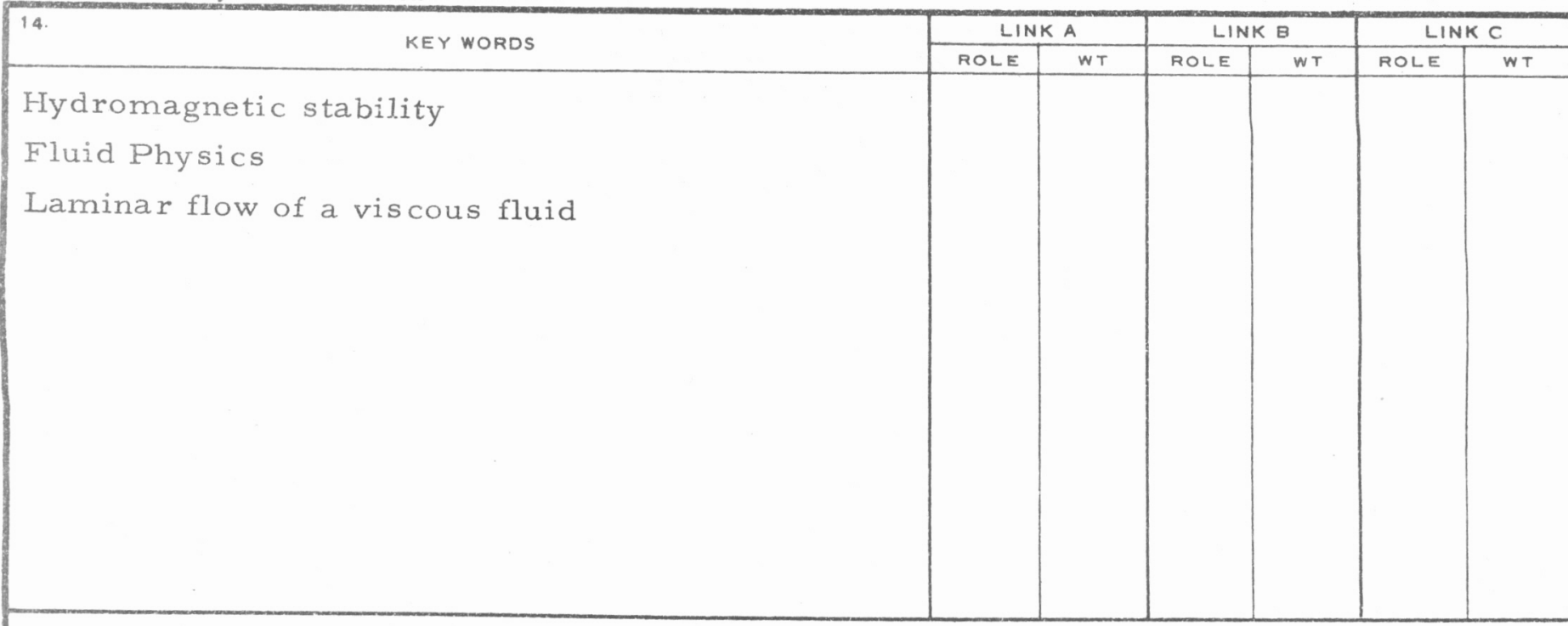

4. ORIGINATING ACTIVITY: Enter the name and address of the contractor, subcontractor, grantee, Department of Defense activity or other organization (corporate author) issuing the report.

2a. REPORT SECURTY CLASSIFICATION: Enter the overall security classification of the report. Indic ate whether "Restricted Data" is included. Marking is to be in accordance with appropriate security regulations.

2b. GROUP: Automatic downgrading is specified in DOD Directive 5200.10 and Armed Forces Industrial Manual. Enter the group number. Also, when applicable, show that optional markings have been used for Group 3 and Group 4 as authorized.

3. REPOR'T TITLE: Enter the complete report title in all capital letters. Titles in all cases should be unclassified. If a meaningful title cannot be selected without classification, show title classification in all capitals in parenthesis immediately following the title.

4. DESCRIPTIVE NOTES: If appropriate, enter the type of report, e.g., interim, progress, summary, annual, or final. Give the inclusive dates when a specific reporting period is covered.

5. AUTHOR(S): Enter the name(s) of author(s) as shown on or in the report. Enter last name, first name, middle initial. If military, show rank and branch of service. The name of the principal author is an ahsolute minimum requirement.

6. REPORT DATE: Enter the date of the report as day, month, year; or month, year. If more than one date appears on the report, use date of publication.

7a. TOTAL NUMBER OF PAGES: The total page count should follow normal pagination procedures, i. e., enter the number of pages containing information.

7b. NUMBER OF REFERENCES: Enter the total number of references cited in the report.

8a. CONTRACT OR GRANT NUMBER: If appropriate, enter the applicable number of the contract or grant under which the report was written.

$8 b, 8 c, 8$ sd. PROJECT NUMBER: Enter the appropriate military department identification, such as project number, subproject number, system numbers, task number, etc.

9a. ORIGINATOR'S REPORT NUMBER(S): Enter the official report number by which the document will be ident ified and controlled by the originating activity. This number must be unique to this report.

9b. OTHER REPORT NUMBER(S): If the report has been assigned any other report numbers (either by the originator or by the sponsor), also enter this number(s).

10. AVAILABILITY/LIMITATION NOTICES: Enter any limitations on further dissemination of the report, other than those imposed by security classification, using standard statements such as:

(1) "Qualified requesters may obtain copies of this report from DDC.'

(2) "Foreign announcement and dissemination of this report by DDC is not authorized."

(3) “U. S. Government agencies may obtain copies of this report directly from DDC. Other qual ified DDC users shall request through

(4) “U. S. military agencies may obtain copies of this report directly from DDC. Other qualified users shall request through

(5) "All distribution of this report is controlled. Qualified DDC users shall request through ."

If the report has been furnished to the Office of Technical Services, Department of Commerce, for sale to the public, indicate this fact and enter the price, if known.

11. SUPPLEMENTARY NOTES: Use for additional explanatory notes.

12. SPONSORING MILITARY ACTIVITY: Enter the name of the departmental project office or laboratory sponsoring (pay ing for) the research and development. Include address.

13. ABSTRACT: Enter an abstract giving a brief and factua! summary of the document indicative of the report, even though it may also appear elsewhere in the body of the technicaire. port. If additional space is required, a continuation sheet shail be attached.

It is highly desirable that the abstract of classified reports be unclassified. Each paragraph of the abstract shall end with an indication of the military security classification of the information in the paragraph, represented as $(T S),(S),(C)$, or (U)

There is no limitation on the length of the abstract. How ever, the suggested length is from 150 to 225 words

14. KEY WORDS: Key words are technically meaningful terms or short phrases that characterize a report and $m a y$ be used as index entries for cataloging the report. Key words must be selected so that no security classification is required. Identi fiers, such as equipment model designation, trade name, mititary project code name, geographic location, may be used as key words but will be followed by an indication of technical context. The assignment of links, rales, and weights is cptional. 